\title{
Do structured arrangements for multidisciplinary peer group supervision make a difference for allied health professional outcomes?
}

This article was published in the following Dove Press journal:

Journal of Multidisciplinary Healthcare

9 October 2013

Number of times this article has been viewed

\author{
Pim Kuipers ${ }^{1,2}$ \\ Susan Pager ${ }^{1}$ \\ Karen Bell ${ }^{3}$ \\ Fiona $\mathrm{Hall}{ }^{4}$ \\ Melissa Kendall2,5,6
}

'Centre for Functioning and Health Research, Metro South Health, Brisbane, Queensland, Australia; ${ }^{2}$ Centre for Community Science, School of Human Services, Griffith University, Queensland, Australia; ${ }^{3}$ Darling Downs Hospital and Health Service, Queensland, Australia; ${ }^{4}$ Allied Health Professions Office of Queensland, Health Service and Innovation Division, Queensland, Australia; ${ }^{5}$ Acquired Brain Injury Outreach Service, Metro South Health, Brisbane, Queensland, Australia; ${ }^{6}$ Transitional Rehabilitation Programme, Metro South Health, Brisbane, Queensland, Australia
Correspondence: Pim Kuipers Centre for Functioning and Health Research, Metro South Health, PO Box 6053, Buranda, Queensland, Australia, 4102

Tel +6I 734062264

Fax +6I 734062267

Email p.kuipers@griffith.edu.au

\begin{abstract}
Peer group supervision, particularly in multidisciplinary formats, presents a potential means of providing professional support, and specifically clinical supervision, for allied health professionals. Debate exists regarding the extent to which the activities of these groups should be formalized. Results drawn from an evaluation of a large-scale peer group supervision initiative are described. Analysis of 192 responses from professionals involved in peer groups indicates that participants in groups that used formal documentation - which adopted the tools provided in training, and particularly those that used formal evaluation of their groups - rated their groups as having better processes and greater impact. Interestingly, multidisciplinary peer groups were rated as having similar impacts, processes, and purposes as the more homogenous single-discipline groups. It is concluded that the implementation of formal arrangements enhances the processes and outcomes of peer groups implemented for professional support and clinical supervision. Multidisciplinary membership of such groups is perceived as equally beneficial as single-discipline groups.
\end{abstract}

Keywords: allied health, professional supervision, clinical supervision, professional support, multidisciplinary

\section{Introduction}

In addition to the measures used to ensure that health professionals have appropriate qualifications and are safe and competent to practice, substantial efforts are directed to ensuring that professionals remain current in their practice. Employers, professional bodies, and professionals themselves seek to foster personal and professional growth through various forms of professional supervision. ${ }^{1}$ In Australia, managers, policymakers, and planners have encouraged the provision of clinical supervision as a means of improving both clinical governance and the ongoing development of individual practitioners. ${ }^{2}$ From an organizational point of view, professional support and clinical supervision are seen as important strategies for improving clinical governance, ${ }^{3}$ maximizing service quality, ${ }^{4}$ and even enhancing recruitment and retention. ${ }^{5}$

There are many ways of providing professional support. In allied health and related settings, professional support strategies have included mentoring, ${ }^{4}$ in-service training, individual professional supervision, journal clubs, ${ }^{6}$ reflective practice activities, ${ }^{7}$ and the implementation of professional standards. ${ }^{8}$ Such activities use courses, conferences, colloquia or workshops, case or program reviews, guidelines, meetings, and direct supervision. ${ }^{9}$

One contemporary approach to clinical supervision is known as peer group supervision (PGS). This approach supports peers as they meet and learn together through 
the sharing of personal and professional experiences, and by reflecting on practice issues. Responsibilities are shared, and the role of facilitator rotates among participants. There are usually structured processes offered to guide the conduct of the group during discussions, and to evaluate the outcomes of the supervision. ${ }^{10}$ The PGS approach differs from other group approaches to professional supervision in that it does not rely on an identified leader or expert. Participants challenge and support each other in improving practice, and they seek to find solutions and act on questions posed in the group. It would appear that such groups may result in positive outcomes in terms of professional behavior and professional identity, ${ }^{11}$ greater resilience to stress, as well as greater autonomy and clarity of function. ${ }^{12}$

One of the key questions in the application of such peeroriented approaches is the degree to which such groups should be deliberately structured or more loosely implemented. For example, in a qualitative study exploring the preferences of paraprofessionals to a similar group-based approach, all of the participants clearly stated a preference for a spontaneous model, and rejected a formally structured or evaluated approach to group-based supervision. ${ }^{13}$ Conversely, there have been suggestions that informal approaches to clinical supervision are not constructive, and may perpetuate existing problems ${ }^{14}$ In terms of outcomes, a recent study documented numerous positive learning and competence outcomes from the implementation of a structured model of clinical supervision for nurses, which used contracts and clear rules about engagement and participation. ${ }^{15}$

While the degree of structure used in clinical supervision is influenced by organizational policy and directives, often the actual implementation is dependent on factors including staff and management preferences and motivation. Factors such as time, resources, logistical issues in a workplace, interpersonal factors, interdisciplinary connections, and constraints, as well as management support and available technology, all influence how clinical supervision is implemented. ${ }^{16}$

The current study formed part of a larger research and evaluation project across the Hospital and Health Services in Queensland, in which a large number of participants undertook PGS training using the New Zealand Coaching and Mentoring Centre Model. ${ }^{17}$ Under this model, participants are responsible for the process, taking turns to be a facilitator, and sharing supervision and responsibilities. ${ }^{18}$ In the research and evaluation project, numerous mechanisms and supports for conducting meetings, activities, and roles were provided. However, in practice, the adoption of formal structures varied across groups, as did the degree of documentation and evaluation. As such, the project was an ideal context in which the following research question could be applied: "Do structured arrangements for allied health group supervision lead to better outcomes for peer group members?"

\section{Methods}

The project within which this study was conducted involved 613 allied health staff who attended PGS training conducted between July 2008 and June 2010. The staff members were invited to complete an annual online survey (2011 and 2012) that assessed their knowledge and use of the PGS program, their satisfaction with it, and any perceived impact it had on their work. For the current study, responses were obtained from those participants who had ongoing involvement in PGS, and in 22 cases, where two annual responses were provided by an individual, only the later response was included (in which their experience of PGS was more extensive). A total of 192 responses (comprising all survey respondents who had undertaken training and were involved in a PGS group) were included in the final sample.

Ethical approval was provided by the Griffith University Human Research Ethics Committee and the Gold Coast Health Service District Human Research Ethics Committee (with site-specific approval established across 23 sites in Queensland).

The materials used in collecting data extracted from the present sample included: (1) demographic questions: profession, years of experience, location, and service context (Table 1); (2) group questions: composition, size, location, and frequency of meetings (Table 2); (3) four questions regarding the degree of structure of the peer group (Table 3 ); and (4) a published measure of satisfaction and perceived outcomes of such models of supervision. This measure, the Clinical Supervision Evaluation Questionnaire (CSEQ), ${ }^{19}$ asks participants to indicate their agreement (on a five-point Likert scale) with 14 statements related to the "Purpose", "Process", and "Impact" of clinical supervision. Initial psychometric analysis indicated that the scale had acceptable internal consistency (Cronbach's alpha $=0.86$ ). Convergent validity was demonstrated through positive correlations of the CSEQ, with a single question assessing overall clinical supervision program satisfaction. Factor analysis supported the three-factor structure of the scale with factors of Purpose, Process, and Impact accounting for $72.4 \%$ of the variance. ${ }^{19}$

Survey data were collected and collated using the LimeSurvey ${ }^{\circledR}$ online survey tool software (Carsten Schmitz, Hamburg, Germany) and took approximately 20 minutes 
Table I Characteristics of participants in the sample

\begin{tabular}{|c|c|c|}
\hline Characteristics of the sample & Number & $\overline{\text { Percent }}$ \\
\hline \multicolumn{3}{|l|}{ Sole practitioner } \\
\hline Yes & 37 & 22 \\
\hline No & 135 & 78 \\
\hline \multicolumn{3}{|l|}{ Sex } \\
\hline Female & 146 & 85 \\
\hline Male & 26 & 15 \\
\hline \multicolumn{3}{|l|}{ New graduate } \\
\hline Yes & 8 & 5 \\
\hline No & 164 & 95 \\
\hline \multicolumn{3}{|l|}{ Level of allied health position } \\
\hline Base grade & 31 & 19 \\
\hline Mid-level & 82 & 49 \\
\hline Senior & 45 & 27 \\
\hline Management & 8 & 5 \\
\hline \multicolumn{3}{|c|}{ Years of experience in current profession } \\
\hline $0-2$ years & 12 & 7 \\
\hline $3-5$ years & 21 & 13 \\
\hline $6-10$ years & 32 & 20 \\
\hline II or more years & 95 & 60 \\
\hline \multicolumn{3}{|l|}{ Allied health profession } \\
\hline Social work & 34 & 20 \\
\hline Occupational therapy & 33 & 19 \\
\hline Physiotherapy & 27 & 16 \\
\hline Psychology & 22 & 13 \\
\hline Dietetics and nutrition & 22 & 13 \\
\hline Speech pathology & 21 & 12 \\
\hline Podiatry & 4 & 2 \\
\hline Other & 7 & 4 \\
\hline
\end{tabular}

for participants to complete. Data were downloaded to IBM SPSS Statistics version 19 (IBM Corporation, Armonk, NY, USA) for analysis. The following dichotomous groups were formed on the basis of responses about the format of peer groups. They included three participant/group variables:

- single-discipline/professional group versus two or more professions represented;

- participants based in a metropolitan area versus those based in a regional/rural PGS group; and

- participants working in the acute/hospital setting versus participants not in the acute/hospital setting.

They also included four variables, indicating adherence to formal arrangements in PGS:

- supervision agreements in place for group members versus no supervision agreements;

- documentation of meetings completed versus no formal documentation completed;

- use of tools and strategies, as intended in the PGS training, versus training tools not used; and

- group activities evaluated/reviewed at some level versus no evaluation of the group.

Independent samples $t$-tests were then used to examine differences on the CSEQ as a total, on subscales, and on individual items. Chi-square comparisons were used to
Table 2 Characteristics of peer group supervision groups in the sample

\begin{tabular}{lll}
\hline Characteristics of the groups & Number & Percent \\
\hline $\begin{array}{l}\text { Size of the group } \\
\text { Number of participants (mean) }\end{array}$ & \\
Number of professions in the group & 110 & $(4.9)$ \\
I & 14 & 63 \\
2 & 18 & 8 \\
3 & 22 & 10 \\
4 & 11 & 13 \\
$4+$ & & 6 \\
Frequency of meetings & 5 & \\
Weekly & 6 & 3 \\
Fortnightly & 111 & 3 \\
Monthly & 48 & 60 \\
Less frequent than monthly & 14 & 26 \\
Ad hoc & & 8 \\
Duration of the meetings & 33 & \\
Less than I hour & 128 & 74 \\
I-2 hours & 8 & 5 \\
2-3 hours & 5 & 3 \\
Other
\end{tabular}

determine whether there were group differences between each of the variables listed. For all analyses, the significance level was set at 0.01 to accommodate and correct for multiple comparisons.

\section{Results}

Tables 1 and 2 provide demographic information about the 192 respondents in this sample, as well as about the characteristics of their PGS groups. Given that the CSEQ is a relatively new scale, reliability was examined in the current sample. Cronbach's alpha values were calculated for each of the subscales and for the total CSEQ. The scale and its subscales demonstrated good internal consistency with alpha values of 0.934 for the total, and $0.761,0.945$, and 0.911 for the Purpose, Process, and Impact subscales, respectively.

Table 3 presents the means and standard deviations for each group on the CSEQ total score and subscales. When examining the differences on the CSEQ, no significant differences were found on the CSEQ total or the subscales between peer groups (comprised of participants of a single discipline) or when compared with groups comprised of two or more disciplines. Individuals from metropolitan locations scored significantly higher on the Impact subscale than did those from regional locations $(t=2.912 ; P=0.004)$; these individuals showed no differences on the Purpose or Process subscales, or on the total CSEQ score. There were no significant differences between those allied health professionals who worked in hospital or acute settings compared with those who worked outside of hospital/acute settings. 


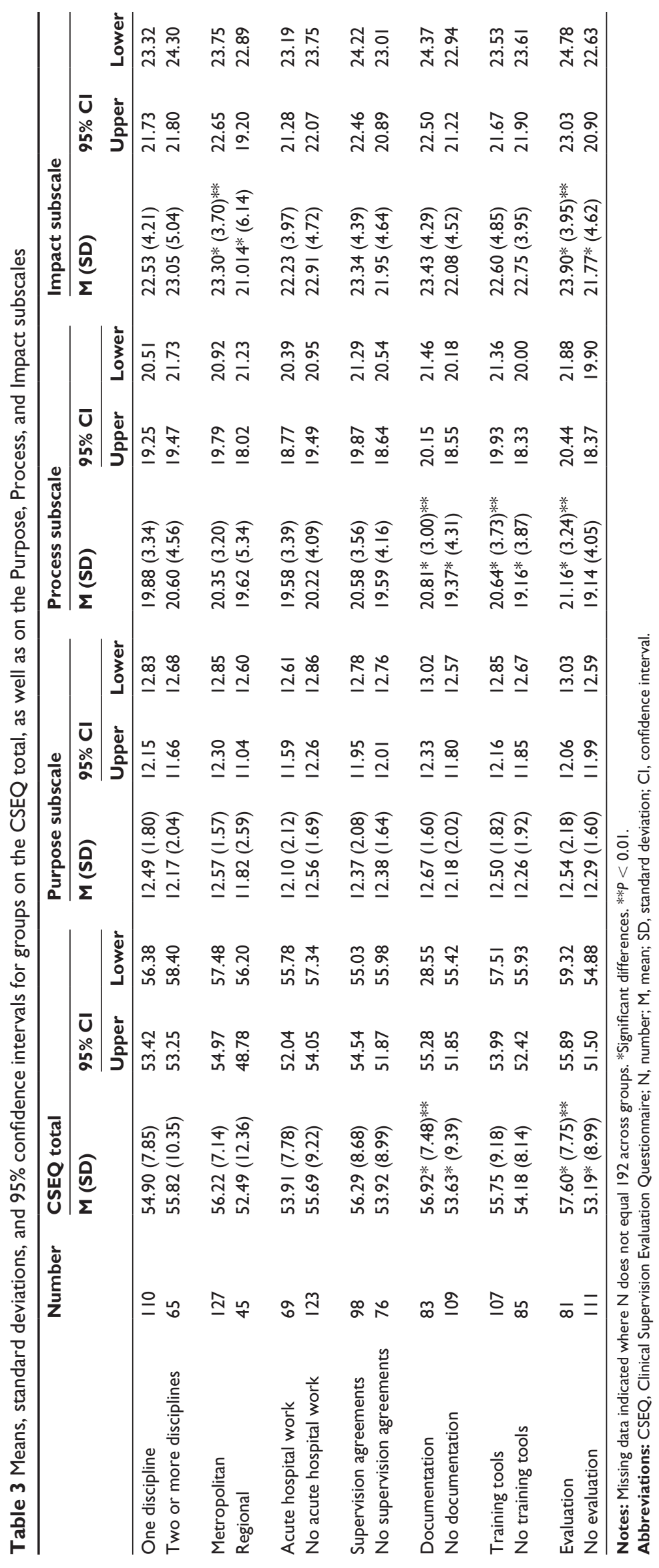


Peer groups with supervision agreements in place did not significantly differ from those which did not have such agreements in terms of the CSEQ total or on any subscale. However, PGS groups that used formal documentation of group supervision meetings scored significantly higher on the CSEQ total $(t=2.615 ; P=0.01)$ and on the Process subscale $(t=2.602 ; P=0.01)$ than groups that did not use formal documentation. Specifically, when exploring these data at the CSEQ item level, it was found that in groups where documentation was completed, participants felt more strongly that their peer group had well established ground rules $(t=3.151 ; P=0.002)$, and that their confidentiality was respected $(t=2.915 ; P=0.004)$.

Peer groups that incorporated training tools, as initially specified, scored significantly higher than groups that did not use the training tools on the Process subscale of the CSEQ $(t=2.684 ; P=0.008)$. At the item level within this subscale, a statistically significant relationship indicated that those participants rated that their peer group had well established ground rules $(t=3.685 ; P<0.001)$.

The greatest number of statistically significant findings was found for the peer groups that evaluated or reviewed their activities at some level. In comparison with those that did not have evaluations or reviews in place, these groups scored significantly higher on the Process subscale $(t=3.713$; $P<0.001)$, the Impact subscale $(t=3.441 ; P=0.001)$, and on the total CSEQ $(t=3.558 ; P=0.008)$. Specifically at the item level, in comparison with unevaluated groups, individuals in peer groups with some form of evaluation in place noted that there were well established ground rules in their groups $(t=2.804 ; P=0.006)$, that there was a greater sense of safety in sharing information $(t=3.197$; $P=0.002)$, that their confidentiality was respected within the group $(t=3.885 ; P<0.001)$, that there was trust between members of the group $(t=3.500 ; P=0.001)$, and that they had greater confidence discussing issues within the group $(t=3.422 ; P=0.001)$. They also noted that their involvement had a positive impact on the quality of their care $(t=3.634$; $P<0.001)$, that it helped them to cope with stresses at work $(t=3.657 ; P<0.001)$, and that they felt more confident in their job $(t=3.895 ; P<0.001)$.

\section{Discussion}

With regard to the four key variables, it is noteworthy that the PGS groups that used a degree of documentation, the tools provided in the PGS training, and some evaluation of the groups rated their groups more highly than those groups that did not. At the item level, this was reflected in participants' views that such groups had well established ground rules and that their confidentiality was respected.

Specifically, the indication of the importance of formal evaluations or reviews in PGS groups is reflected in the significant findings observed at the CSEQ item level. That is, those individuals in peer groups that used some form of evaluation noted that there were well established ground rules, and that there were greater levels of safety, confidentiality, and trust between members of the group, and that they had greater confidence when discussing issues within the group. This increased sense of satisfaction and professional support aligns with the supportive/restorative functions of supervision, as described in Proctor's model, ${ }^{20}$ and reinforces previous studies that noted such benefits of effective supervision. ${ }^{21-23}$

At the service delivery level, participants of groups with evaluations in place expressed the view that their supervision had a positive impact on the quality of care, helped them to cope with stresses, and that they felt more confident in their job. While some authors have linked such enhanced practice and reduced stress with clinical supervision in general, ${ }^{7,24}$ the current study found that they were specifically associated with more formally evaluated groups.

The use of formal documentation among the PGS groups in this study was associated with higher overall CSEQ ratings and higher ratings on the Process subscale. Further, the use of tools and strategies, as provided in the original PGS training, was also associated with higher Process subscale ratings. These findings provide support for the implementation and maintenance of formal arrangements in PGS groups. Specifically, they underscore the importance of attending to the processes of training and the formal use of structures ${ }^{25}$ in the implementation of PGS.

Likewise, these findings provide considerable support for the importance of some degree of evaluation in PGS. Participants in PGS groups who evaluated what they were doing at some level rated their groups higher on the CSEQ total, as well as on the Process and Impact subscales. This suggests that evaluating was associated with groups that were perceived as having a greater impact and that operated more effectively. This finding provides confirmation for studies that have been advocating such measures in clinical supervision. ${ }^{26,27}$

There was an indication that metropolitan participants rated the impact of PGS groups more highly than regional and rural participants. This finding was somewhat counterintuitive, given that regional participants would likely have access to fewer professional development resources and, therefore, 
may value PGS groups more highly. However, given that regional participants had fewer options (as reflected in their comparatively higher participation rate), they may have been a more diverse group than their metropolitan counterparts, who may have specifically chosen PGS in preference to other options, and thus derived maximum benefit from the group. Additionally, it is possible that rural participants, many of whom work in smaller multidisciplinary settings, have greater access to informal professional support across professions, reducing their perceived benefit from PGS.

The finding that single-discipline PGS groups were not significantly different from groups with more than one professional discipline on the CSEQ total score, or with more than one professional discipline on the subscale scores, is also noteworthy. It might have been expected that groups that were more homogeneous would also be rated as having better processes, clearer purpose, and greater impact. Interestingly, the current results did not find this, despite the fact that there were a comparatively large number of single-discipline groups. While it may be an artifact of the formal structure in the current PGS approach, the ratings of participants in multidisciplinary groups did not statistically differ from single-discipline groups. This finding provides support for the trend towards multidisciplinary approaches to supervision. ${ }^{28}$ It also suggests that studies that have only used a single-discipline approach to group supervision ${ }^{11,27}$ may have achieved similar outcomes had they used multidisciplinary groups.

Given that the current study is an analysis of service evaluation data, findings should be interpreted in light of the methodological limitations. As in all such voluntary surveys, the results may reflect considerable response bias, with participants from certain groups (and potentially the more successful groups) more likely to respond than others. Further, the response rate within each PGS group was not monitored, so some groups or certain types of groups may have provided proportionally more responses than others. Importantly, no causal relationships for the findings should be implied. For example, it is not possible to distinguish whether more successful and impactful groups were more likely to evaluate their groups, or whether those groups that evaluated their activities became more impactful.

It is important to note that this study is relatively novel in terms of its methodology and focus, so further studies will be required to establish firm conclusions. Such studies should investigate the longer-term impact of this approach, as well as examine the impact that formal arrangements have on the working life of health professionals. Despite this, the strength of the associations found in this study would suggest that promoting the use of more formal arrangements and structures for PGS is a good starting point.

\section{Conclusion}

The current findings suggest that supervision, and specifically PGS, must be well implemented with adequate infrastructure (such as formal evaluation mechanisms and management support) to be meaningful. Clearly, there is much more research that needs to be done on the process and impact of PGS. Further research may look at issues such as the learning styles of participants, ${ }^{11}$ gender differences and preferences for professional supervision, ${ }^{29}$ the professional composition of the groups,${ }^{11}$ and connections between supervision and organizational goals, as well as personality and relationship types of the participants. ${ }^{14}$

\section{Acknowledgments}

The authors are very thankful to Dr Simon Horton for assistance with the use of the Clinical Supervision Evaluation Questionnaire (CSEQ). This survey has been developed in the UK with the University of East Anglia. The support of Queensland Health is also gratefully acknowledged.

\section{Disclosure}

The authors report no conflicts of interest in this work.

\section{References}

1. Steenbergen K, Mackenzie L. Professional support in rural New South Wales: perceptions of new graduate occupational therapists. Aust $J$ Rural Health. 2004;12(4):160-165.

2. White E, Winstanley J. Implementation of Clinical Supervision: educational preparation and subsequent diary accounts of the practicalities involved, from an Australian mental health nursing innovation. J Psychiatr Ment Health Nurs. 2009;16(10):895-903.

3. McSherry R, McSherry W, Pearce P. Can clinical governance act as a cultural barometer? Nurs Times. 2002;109(19):12-15.

4. Milne D. An empirical definition of clinical supervision. Br J Clin Psychol. 2007;46(Pt 4):437-447.

5. Battye KM, McTaggart K. Development of a model for sustainable delivery of outreach allied health services to remote north-west Queensland, Australia. Rural Remote Health. 2003;3(3):194.

6. Lizarondo LM, Kumar S, Grimmer-Somers K. Supporting allied health practitioners in evidence-based practice: a case report. Int $J$ Ther Rehabil. 2009;16(4):226-236.

7. Clouder L, Sellars J. Reflective practice and clinical supervision: an interprofessional perspective. J Adv Nurs. 2004;46(3):262-269.

8. Kirk SFL, Eaton J, Auty L. Dietitians and supervision: should we be doing more? J Hum Nutr Diet. 2000;13(5):317-322.

9. Fitzgerald K, Hudson L, Hornsby D. A Study of Allied Health Professionals in Rural and Remote Australia. Deakin West, Australia: Services for Australian Rural and Remote Allied Health Incorporated; 2000.

10. Kilminster S, Cottrell D, Grant J, Jolly B. AMEE Guide No 27: Effective educational and clinical supervision. Med Teach. 2007;29(1):2-19.

11. Hølge-Hazelton B, Tulinius C. Individual development of professionalism in educational peer group supervision: a multiple case study of GPs. Int J Family Med. 2012;2012:792018. 
12. Arvidsson B, Skärsäter I, Oijervall J, Fridlund B. Process-oriented group supervision implemented during nursing education: nurses' conceptions 1 year after their nursing degree. J Nurs Manag. 2008;16(7): 868-875.

13. Umlah CA. Supervision of Paraprofessionals In the Human Service Field: A Qualitative Approach. Winnipeg, MB: University of Manitoba; 2006.

14. Clutterbuck D. Formal V Informal Mentoring: Time to Shift the Debate? Available from: http://scottishmentoringnetwork.co.uk/assets/ downloads/resources/formal-v-informal-mentoring.pdf. Accessed December 20, 2012.

15. Andersson CS, Danielsson A, Hov R, Athlin E. Expectations and experiences of group supervision: Swedish and Norwegian preceptors' perspectives. J Nurs Manag. 2013;21(2):263-272. Burnham, UK 2006.

16. Jones K, Donnellan H, Owens C. The first year in practice: exploring effective supervision - a practice toolkit for newly qualified social workers (NQSWs) and line managers published as a result of a Skills for Care South West project - 2008. Project report. Leeds, UK: Skills for Care 2009. Available from: http://eprints.uwe.ac.uk/7465/1/SW_NQSW. Accessed December 20, 2012.

17. McNicoll A. The Power of Peer Supervision - No-one Knows as Much as All of Us. Background Paper for Workshop. Auckland, New Zealand: New Zealand Mentoring Centre; 2008. Available from: http://www. coachingmentoring.co.nz/files/NZMC-power-of-peer-supervisionpaper-2008.pdf. Accessed May 14, 2013.

18. Driscoll J, editor. Practising Clinical Supervision: A Reflective Approach for Healthcare Professionals. 2nd ed. Sydney, Australia: Bailliere Tindall Elsevier; 2007.

19. Horton S, de Lourdes Drachler M, Fuller A, de Carvalho Leite JC. Development and preliminary validation of a measure for assessing staff perspectives on the quality of clinical group supervision. Int $J$ Lang Commun Disord. 2008;43(2):126-134.
20. Proctor B. Supervision: a co-operative exercise in accountability. In: Enabling and Ensuring: Supervision in Practice (eds Marken M. \& Payne M.), pp. 21-34. National Youth Bureau and Council for Education and Training in Youth and Community Work, Leicester, UK.

21. White E, Roche M. A selective review of mental health nursing in New South Wales, Australia, in relation to clinical supervision. Int J Ment Health Nurs. 2006;15(3):209-219.

22. Cleary M, Freeman A. The cultural realities of clinical supervision in an acute inpatient mental health setting. Issues Ment Health Nurs. 2005;26(5):489-505.

23. Kilminster SM, Jolly BC. Effective supervision in clinical practice settings: a literature review. Med Educ. 2000;34(10):827-840.

24. Severinsson EI, Kamaker D. Clinical nursing supervision in the workplace - effects on moral stress and job satisfaction. J Nurs Manag. 1999;7(2):81-90.

25. Lynch L, Happell B. Implementation of clinical supervision in action: Part 2: implementation and beyond. Int J Ment Health Nurs. 2008;17(1): 65-72.

26. Edwards D, Burnard P, Hannigan B, et al. Clinical supervision and burnout: the influence of clinical supervision for community mental health nurses. J Clin Nurs. 2006;15(8):1007-1015.

27. Ritter S, Norman IJ, Rentoul L, Bodley D. A model of clinical supervision for nurses undertaking short placements in mental health care settings. J Clin Nurs. 1996;5(3):149-158.

28. Miller TW, Miller JM, Burton D, Sprang R, Adams J. Telehealth: a model for clinical supervision in allied health. The Internet Journal of Allied Health Sciences and Practice. 2003;1(2):1-8.

29. Arvidsson B, Baigi A, Skärsäter I. Changes in the effects of processoriented group supervision as reported by female and male nursing students: a prospective longitudinal study. Scand J Caring Sci. 2008;22(3):437-444.
Journal of Multidisciplinary Healthcare

\section{Publish your work in this journal}

The Journal of Multidisciplinary Healthcare is an international, peerreviewed open-access journal that aims to represent and publish research in healthcare areas delivered by practitioners of different disciplines. This includes studies and reviews conducted by multidisciplinary teams as well as research which evaluates the results or conduct of such teams or health-

\section{Dovepress}

care processes in general. The journal covers a wide range of areas and welcomes submission from practitioners at all levels, from all over the world. The manuscript management system is completely online and includes a very quick and fair peer-review system. Visit http://www.dovepress. com/testimonials.php to read real quotes from published authors. 